\title{
Outcomes of the Surgical Treatment of Periprosthetic Fractures Around the Knee with Locking Plates: A Single Centre Experience
}

\author{
Atalay IB, MD, Ozturk R, MD, Yapar A, MD, Karakoc Y, MD, Eksioglu MF, MD \\ Department of Orthopaedics and Traumatology, Dr Abdurrahman Yurtaslan Onkoloji Egitim ve Arastirma \\ Hastanesi, Ankara, Turkey
}

This is an open-access article distributed under the terms of the Creative Commons Attribution License, which permits unrestricted use,
distribution, and reproduction in any medium, provided the original work is properly cited

Date of submission: 31st January 2019

Date of acceptance: 06th May 2021

\begin{abstract}
Introduction: Surgical treatment options for periprosthetic fractures (PPF) include internal fixation with plate, intramedullary nailing and revision arthroplasty. We aimed at evaluating the surgical outcomes of patients who we had treated PPF with locking compression plates (LCP).

Materials and methods: Twenty patients with PPF after primary total knee arthroplasty (TKA) between 2009 and 2016 were included in to the study. Knee Society Knee Scoring System (KSKSS) was used in the evaluation of radiologic and functional outcomes. There were periprosthetic supracondylar femoral fractures in 15 patients, and that of tibial fractures in 5 patients. For internal fixation, locking compression plate was preferred.

Results: The mean age was 69 (range 61 to 78 ) years and the mean follow-up period was 72.25 (range 24 to 110) months. Union was achieved by 15.8 weeks in all the cases. Superficial infection and implant fracture were each seen in two patients. Revision operations were done to those patients with implant fracture. Mean KSKSS was 81.4 (75-87) and the mean functional score was 78.75 (75-85). Degenerative osteoarthritis patients were found to have higher age values than post-traumatic osteoarthritis patients $(\mathrm{p}=0.001)$. When the union times were compared, it was found that the degenerative osteoarthritis patient group had a significantly shorter union than the post-traumatic osteoarthritis patient group $(\mathrm{p}=0.036)$.

Conclusion: Internal fixation with LCP is an effective treatment method in managing of PPF for patients with good bone stock. Rigid fixation should be done with the right surgical technique and an early movement must be initiated so that a good function can be achieved.
\end{abstract}

Keywords: total knee arthroplasty, periprosthetic fracture, locking compression plates

\section{INTRODUCTION}

In recent years, the numbers of arthroplasty implementations have been increasing in parallel to increasing life expectancy and the increasing quality of life. Therefore, PPF incidence is also increasing ${ }^{1}$.

The incidence of periprosthetic fractures (PPF) after total knee arthroplasty (TKA) is between $0.3 \%-2.5 \%$. The most common fracture after knee arthroplasty is supracondylar femoral fractures and they include fractures up to $15 \mathrm{~cm}$ from the joint ${ }^{2,3}$. This is followed by patella fractures and proximal tibial fractures ${ }^{4}$.

Fracture may be seen intra-operatively or post-operatively. As early fractures generally seen from the surgical technique, late fractures are due to low energy traumas. Also, the factors leading to fracture can be classified as the ones related to patient or the ones related to the surgery. Risk factors related to patient are osteoporosis, rheumatoid arthritis, neurologic diseases, steroid usage, smoking, immunosuppression, and female sex. Surgical factors are excessive bone resection and anterior femoral notching ${ }^{1,4}$.

Although the intra-operative fractures are relatively less displaced, post-operative fractures are more fragmented fractures accompanied by soft tissue trauma. Also, the fixation of prosthesis may be affected. Arthroplasty patients must be mobilised early due to the fact that they are elderly patients with accompanying systemic diseases and their general medical conditons. Moreover, accompanying osteoporosis makes fixation difficult and mobilisation late. These factors complicate the management of PPF after arthroplasty.

Corresponding Author: Ismail Burak Atalay, Department of Orthopaedic and Traumatology, Dr Abdurrahman Yurtaslan Onkoloji Egitim ve Arastirma Hastanesi, Demetevler, Vatan Cd., 06200 Yenimahalle/Ankara, Turkey

Email: drburakatalay@gmail.com 


\section{MATERIALS AND METHODS}

Between January 2009 and December 2016, 20 patients with informed consent who have PPF after primary TKA have been retrospectively evaluated. Sixteen of them were female and four of them were male. The time elapsed from the first surgery to the fracture, age, follow-up period, fracture localisation and the complications were evaluated. All patients were divided into two groups as patients between 60-69 years and patients aged 70 and over. Radiographic and functional outcomes evaluations are set according to Knee Society Knee Scoring System (KSKSS) ${ }^{5}$. According to this scoring system, in knee scoring; pain, flexion contracture (if present), extension range, total range of motion, varusvalgus angulations, and stability parameters were evaluated. On the other hand, in functional scoring, walking capacity, going up and down through stairs, walking apparatus usage were evaluated. According to these scoring; 60 points and below are considered as poor, 60-69 points as moderate, 7079 points as good, 80-100 points are perfect.

For all our patients on first application, physical examination, and two-direction conventional direct graphs were applied. In 15 cases PPF was seen as supracondylar femoral fracture, on the other hand it was periprosthetic tibial fracture for 5 cases. Twelve of 15 supracondylar femoral fractures were Lewis and Rorabeck ${ }^{6}$ type 2 fractures, 3 was type 1 and internal fixation with Locking compression plate (LCP) with minimal invasive technique was done to all the fractures (Fig. 1). No prosthesis cut-off was seen after fracture. Tibial fractures were Felix type $3 \mathrm{~A}$ fractures ${ }^{7}$. Due to the fact that prosthesis stability was strong, internal fixation with LCP with minimal invasive technique was applied for these fractures too (Fig. 2). Post-operative follow-ups were done monthly.

Statistical analysis was performed using the IBM SPSS version 22.0 software [IBM Corp, Armonk, NY, USA]. Categorical variables were expressed in number and percentage, while continuous variables were expressed in mean \pm standard deviation (SD) and median (min-max) values. The relevance of continuous variables to normal distribution was evaluated using the visual (histogram and probability graphics) and analytical methods (KolmogorovSmirnov/Shapiro-Wilk tests). For categorical variables, whether there was a difference with respect to frequency between the groups was compared using the chi-square test. The Mann-Whitney U test was used for the comparison of abnormally distributed data between the groups. The Wilcoxon test was used to evaluate the change in pain score before and after treatment. A $p$ value of $<0.05$ was considered statistically significant.

\section{RESULTS}

The mean age of patients was 69 years (range, 61-78 years) and the mean follow-up period was 72.3 months (range, 24-
110 months). In none of the patients there had been a complication post-operatively and the fracture reason was simple fall in all of the cases. The time from TKA to the fracture was 45 months (range, 10-84 months). The indication of implementing TKA for 6 patients was posttraumatic osteoarthritis, and it was degenerative osteoarthritis for 14 patients. In two patients, superficial infection findings characterised by hyperemia over the skin and slight edema were observed in the follow-ups. No fistula or drainage was observed. Those patients were hospitalised and given parenteral antibiotic therapy. Symptoms of the two patients were totally alleviated. One of the patients operated for tibial fractures came back with implant insufficiency second month post-operatively and so came back the other one, third month post-operatively. For these two patients, iliac autogenous grafting and internal fixation was implemented. In all the patients union was obtained by 15.8 months (range, 12-24 months) months on average. The mean range of motion was $96.50^{\circ}$ (range, $80^{\circ}-110^{\circ}$ ). KSKSS was 81.4 (range, 75-87) and the mean functional score was 78.75 (range, 75-85) (Table I).

There was no statistically significant relationship between union time, age, knee score, functional score, flexion range of motion degree and PPF-time ( $p>0.05$ ) (Table II). The results of the comparison analyses between patient groups by diagnosis and age are presented in Table III. Degenerative osteoarthritis patients were found to have higher age values than posttraumatic osteoarthritis patients $(p<0.001)$. There was no significant difference between the sex distributions of both diagnostic groups and age groups $(p=0.549, p=0.285$, respectively). When the union times were compared, it was found that the degenerative osteoarthritis patients group had a significantly shorter union time than the posttraumatic osteoarthritis patients group $(\mathrm{p}=0.036)$. Union time was similar in both age groups $(\mathrm{p}=0.194)$ (Table III). Knee score $(p=0.253$ and $p=0.571)$ and functional score $(p=0.109$ and $\mathrm{p}=0.436$ ) was found to be similar between diagnosis groups and age groups (Fig. 3).

\section{DISCUSSION}

Treatment of periprosthetic fractures around the knee is challenging because of the complex fracture morphology, high rates of injury associated with osteopenia, and variability of injury patterns $s^{4}$. In this study, we aimed to investigate the results of surgical treatment of periprosthetic fractures of the knee with locking plates. Similar to the literature, this method can be applied in periprosthetic fractures and the results are good. Considering factors such as periprosthetic fractures around the knee, fracture site, type of patient age, they are most often treated with a locked plate or retrograde intramedullary nail (some distal femoral periprosthetic fractures ${ }^{4,8-12}$. These methods are superior to cast immobilisation, external fixation, dynamic compression plate fixation, and dynamic condylar screw fixation. 
Table I: Baseline characteristics

\begin{tabular}{|c|c|}
\hline Parameters $(n=20)$ & \\
\hline \multicolumn{2}{|l|}{ Age, year } \\
\hline Mean $\pm s d$ & $69.0 \pm 5.5$ \\
\hline Median (min-max) & $70.0(61.0-78.0)$ \\
\hline \multicolumn{2}{|l|}{ Gender, n (\%) } \\
\hline Male & $4(20.0)$ \\
\hline Female & $16(80.0)$ \\
\hline \multicolumn{2}{|l|}{ Diagnosis, n (\%) } \\
\hline Osteoarthritis & $14(70.0)$ \\
\hline Post-traumatic osteoarthritis & $6(30.0)$ \\
\hline \multicolumn{2}{|l|}{ PPF time, month } \\
\hline Mean \pm sd & $45.0 \pm 20.2$ \\
\hline Median (min-max) & $47.5(10.0-84.0)$ \\
\hline \multicolumn{2}{|l|}{ Treatment, (\%) } \\
\hline Open reduction, internal fixation & $18(90.0)$ \\
\hline Open reduction, internal fixation + AutoGraft & $2(10.0)$ \\
\hline \multicolumn{2}{|l|}{ Union time, week } \\
\hline Mean \pm sd & $15.8 \pm 2.6$ \\
\hline Median (min-max) & $15.5(12.0-24.0)$ \\
\hline \multicolumn{2}{|l|}{ Follow-up time, month } \\
\hline Mean $\pm s d$ & $72.3 \pm 25.1$ \\
\hline Median (min-max) & $68.5(24.0-110.0)$ \\
\hline \multicolumn{2}{|l|}{ Knee score } \\
\hline Mean \pm sd & $81.5 \pm 3.8$ \\
\hline Median (min-max) & $80.0(75.0-87.0)$ \\
\hline \multicolumn{2}{|l|}{ Functional score } \\
\hline Mean \pm sd & $78.8 \pm 3.9$ \\
\hline Median (min-max) & $80.0(75.0-85.0)$ \\
\hline \multicolumn{2}{|l|}{$f-R O M,^{\circ}$} \\
\hline Mean \pm sd & $96.5 \pm 9.3$ \\
\hline Median (min-max) & $97.5(80.0-110.0)$ \\
\hline
\end{tabular}

sd: standard deviation

PPF time: Time elapsed between the first fracture and the arthroplasty

f-ROM: Flexion range of motion

Table II: Spearman's Correlation Coefficient between Age, Knee score, Functional score, Flexion range of motion degrees, PPF time and Union time

\begin{tabular}{|lcc|}
\hline $\mathbf{N}=\mathbf{2 0}$ & $\mathbf{r}$ & Union time \\
\hline Age & -0.340 & $\mathbf{p}$ \\
Knee score & -0.366 & 0.142 \\
Functional score & -0.187 & 0.113 \\
Flexion range of motion degree & -0.374 & 0.429 \\
PPF time & -0.129 & 0.104 \\
\hline
\end{tabular}

r: Spearman's correlation coefficient

PPF time: Time elapsed between the first fracture and the arthroplasty

We preferred a locking plate instead of a nail for periprosthetic fractures around the knee. Because the bone quality of the patients was good and the fractures were displaced. In addition, the application of intramedullary nails is difficult because of the narrowed or closed medullary area due to total knee replacement. Because the notch should be extended frequently in nail application and this leads to concerns about early prosthesis loosening ${ }^{11,13}$. Furthermore, the locked compression plate is inserted through a small incision using a minimally invasive technique, thereby minimising damage to the periosteal blood supply and improving healing. As the plate is pre-shaped, it helps to reduce fracture fragments. Multiple screws can be placed at different angles, helping to prevent displacement and varus collapse of fracture fragments ${ }^{8,14}$. For two patients of ours that revised with more taller locking plates due to plate insufficiency we had also implemented iliac autogenous grafting due to insufficient bone reserve and obtained union in 20th and 24th weeks in order.

Traditional plate fixations are prone to varus collapse ${ }^{15}$. In the literature it has been reported that non-union rates are high with conventional plates. Figgie $e t$ al ${ }^{16}$ have reported in their 10-patient series that non-union rate was $50 \%$ with 
Table II: Spearman's Correlation Coefficient between Age, Knee score, Functional score, Flexion range of motion degrees, PPF time and Union time

\begin{tabular}{|c|c|c|c|}
\hline \multirow[t]{2}{*}{$\mathrm{N}=\mathbf{2 0}$} & \multicolumn{2}{|c|}{ Diagnosis } & \multirow[t]{2}{*}{$\mathbf{P}$} \\
\hline & $O A(n=14)$ & PTOA $(n=6)$ & \\
\hline Age, year & & & 0.0011 \\
\hline Mean $\pm s d$ & $71.8 \pm 4.0$ & $62.5 \pm 1.0$ & \\
\hline Median (min-max) & $72.0(65.0-78.0)$ & $62.5(61.0-64.0)$ & \\
\hline Gender, n (\%) & & & 0.5492 \\
\hline Male & $2(14.3)$ & $2(33.3)$ & \\
\hline Female & $12(85.7)$ & $4(66.7)$ & \\
\hline PPF time, month & & & 0.8041 \\
\hline Mean \pm sd & $44.5 \pm 17.6$ & $46.2 \pm 27.2$ & \\
\hline Median (min-max) & $47.5(10.0-84.0)$ & $47.0(11.0-80.0)$ & \\
\hline Knee score & & & 0.2531 \\
\hline Mean \pm sd & $80.9 \pm 3.5$ & $82.8 \pm 4.5$ & \\
\hline Median (min-max) & $80.0(75.0-87.0)$ & $85.0(75.0-87.0)$ & \\
\hline Functional score & & & 0.1091 \\
\hline Mean \pm sd & $77.8 \pm 3.8$ & $80.8 \pm 3.8$ & \\
\hline Median (min-max) & $75.0(75.0-85.0)$ & $80.0(75.0-85.0)$ & \\
\hline$f-R O M,^{\circ}$ & & & 0.4231 \\
\hline Mean \pm sd & $95.4 \pm 9.1$ & $99.2 \pm 10.2$ & \\
\hline Median (min-max) & $95.0(80.0-110.0)$ & $100.0(85.0-110.0)$ & \\
\hline Union time, week & & & 0.0361 \\
\hline Mean \pm sd & $15.1 \pm 2.0$ & $17.5 \pm 3.3$ & \\
\hline Median (min-max) & $14.0(12.0-20.0)$ & $16.0(15.0-24.0)$ & \\
\hline Follow-up time, month & & & 0.6801 \\
\hline \multirow{4}{*}{$\begin{array}{l}\text { Mean } \pm \text { sd } \\
\text { Median }(\min -\max )\end{array}$} & $73.4 \pm 24.0$ & $69.5 \pm 29.7$ & \\
\hline & $68.5(24.0-110.0)$ & $71.5(24.0-110.0)$ & \\
\hline & \multicolumn{2}{|c|}{ Age } & \\
\hline & 60-69 Ages $(n=9)$ & $\geq 70(n=11)$ & \\
\hline Gender, n (\%) & & & 0.2852 \\
\hline Male & $6(66.7)$ & $10(90.0)$ & \\
\hline Female & $3(33.3)$ & $1(9.1)$ & \\
\hline PPF time, month & & & 0.6481 \\
\hline Mean \pm sd & $47.7 \pm 26.9$ & $42.8 \pm 13.6$ & \\
\hline Median (min-max) & $48.0(11.0-84.0)$ & $47.0(10.0-61.0)$ & \\
\hline Knee score & & & 0.5711 \\
\hline Mean \pm sd & $81.9 \pm 4.6$ & $81.1 \pm 3.3$ & \\
\hline Median (min-max) & $85.0(75.0-87.0)$ & $80.0(75.0-87.0)$ & \\
\hline Functional score & & & 0.4361 \\
\hline Mean \pm sd & $79.4 \pm 3.9$ & $78.2 \pm 4.0$ & \\
\hline Median (min-max) & $80.0(75.0-85.0)$ & $75.0(75.0-85.0)$ & \\
\hline$f-R O M,^{\circ}$ & & & 0.6411 \\
\hline Mean $\pm s d$ & $95.6 \pm 10.4$ & $97.3 \pm 8.8$ & \\
\hline Median (min-max) & $95.0(80.0-110.0)$ & $100.0(80.0-110.0)$ & \\
\hline Union time, week & & & 0.1941 \\
\hline Mean \pm sd & $16.6 \pm 3.0$ & $15.2 \pm 2.2$ & \\
\hline Median (min-max) & $16.0(14.0-24.0)$ & $14.0(12.0-20.0)$ & \\
\hline Follow-up time, month & & & 0.4701 \\
\hline Mean \pm sd & $76.9 \pm 28.0$ & $68.5 \pm 23.1$ & \\
\hline Median (min-max) & $88.0(36.0-108.0)$ & $65.0(24.0-110.0)$ & \\
\hline
\end{tabular}

${ }^{1}$ Mann-Whitney $U$ test

${ }^{2}$ Chi-Square Test

OA: Osteoarthritis PTOA: Post-traumatic osteoarthritis

traditional plates. Ricci et $a l^{9}$ 24-patient series of supracondylar femoral fractures have reported non-union rate $86 \%$. Fixed-angle blade plates or $95^{\circ}$ condylar plates can prevent varus collapse, but are difficult to be placed in the presence of a prosthesis ${ }^{16}$.
Kregor et al implement locking plate to 103 patients for distal femoral fracture and they observed non-union requiring graft in only one patient ${ }^{10}$. Agarwal et $a l^{8}$ in their 20-patient series have implemented LCP for 11 patients and reported $100 \%$ union rate. We also implemented internal fixation with locking plates for 15 supracondylar femoral 

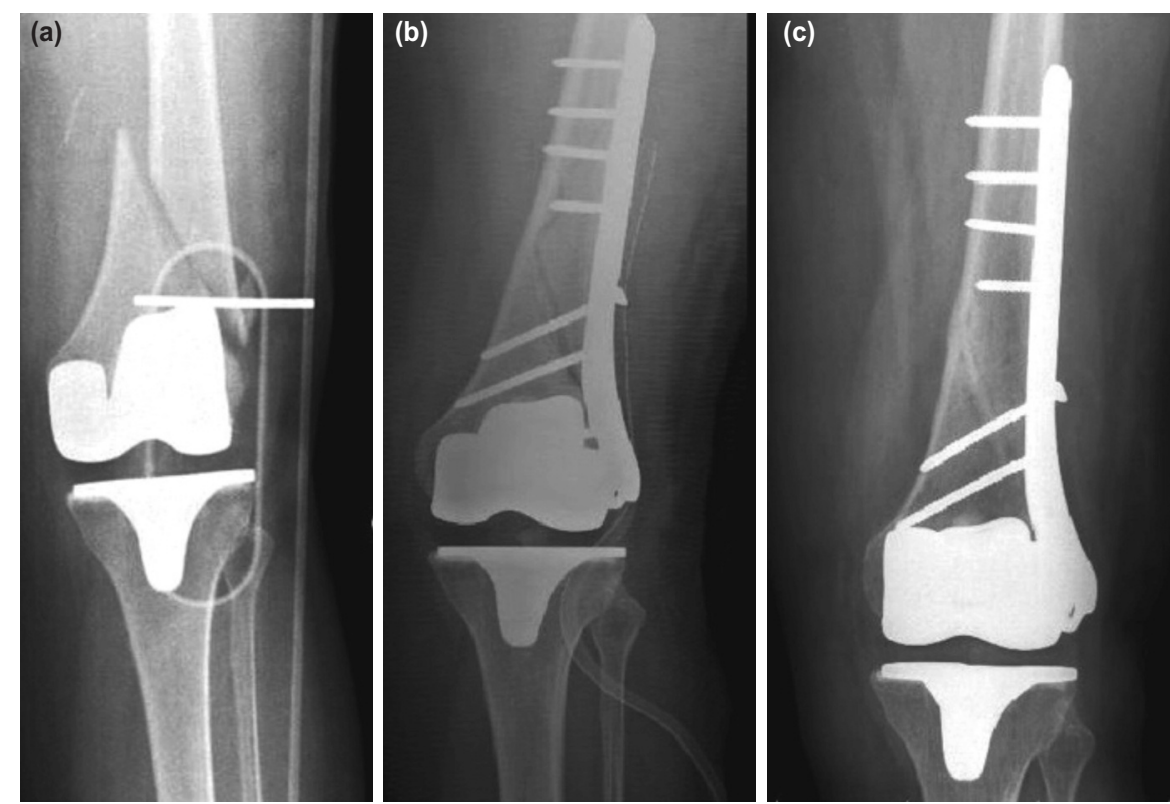

Fig. 1: (a) Lewis Rorabeck Type 2 supracondylar femoral periprosthetic fracture. (b) Post-operative first day radiography. (c) 16th week radiography.
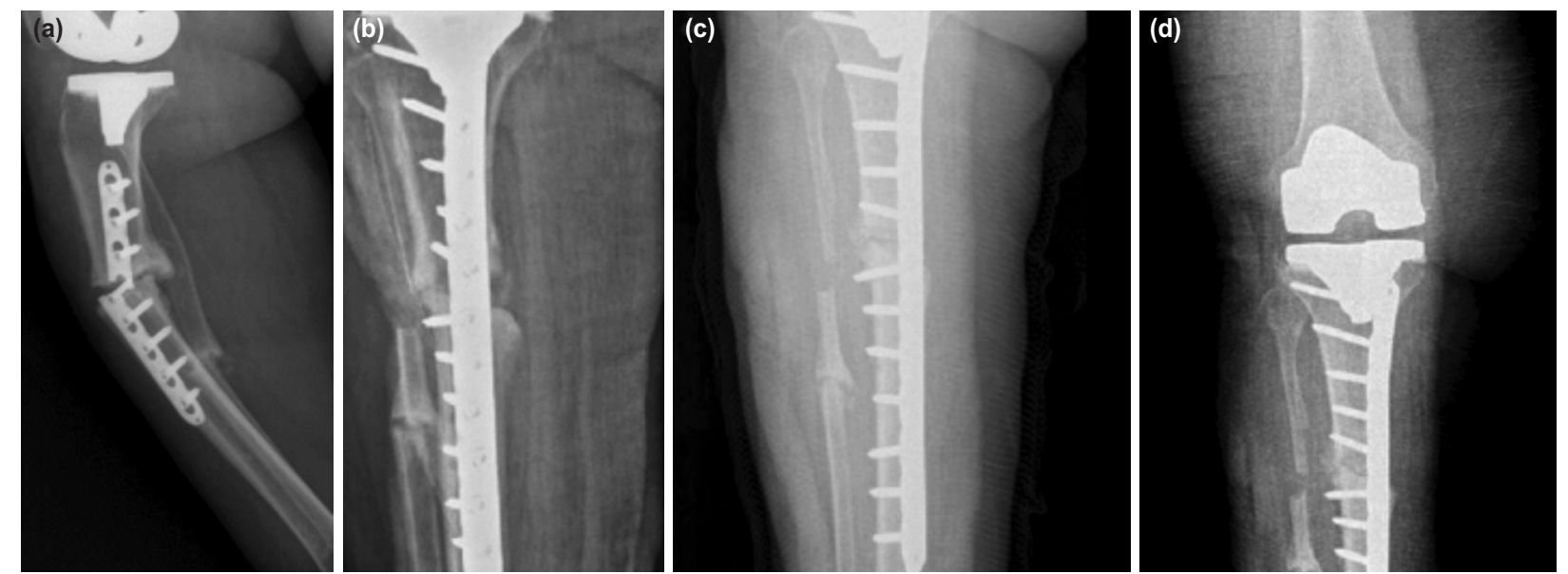

Fig. 2: (a) Implant failure after operation for Felix type 3 periprosthetic fracture. (b) Internal fixation by means of iliacautogenous grafting and locking compression plate (c) 16th week radiography. (d) 24th week radiography.

and 5 tibial PPF, and have obtained union in all patients. In our results, we did not encounter any complication such as varus collapse.

There are also articles in the literature that report high rates of complications after treatment of periprosthetic fractures with locking plates ${ }^{8,12}$. Non-union, delayed union, deep infection and implant failure have been reported. In our study, we did not see any deep infection. We detected superficial infection in two patients that we could treat with antibiotic therapy. We assigned implant failure in two patients and in these cases, we performed iliac autogenous grafting and revision with longer plates. We achieved complete union in these two patients.

Periprosthetic supracondylar femoral fractures are frequent in patients over 60 years old or patients with osteoporosis.
Although they are generally seen after low energy traumas, traffic accidents and rehabilitation manoeuvres after arthroplasty are also risk factors for supracondylar femoral fractures ${ }^{17}$. It has been reported in the biomechanical studies concerning with anterior femoral notching that notching that is deeper that $3 \mathrm{~mm}$ and around the end point of prosthesis leads to high level of stress and increases the risk of fracture ${ }^{18}$.

In the supracondylar femoral fracture, Lewis and Rorabeck classification is used. According to this classification, fractures that are non-displaced and without cut-off are type 1, displaced but without cut-off are type 2, displaced or/nondisplaced with cut-off fractures are type 3. Six of our patients were type 2 and one was type 1. Periprosthetic tibial fractures are less common. It is seen especially after revision knee arthroplasty and the most important reasons are trauma 

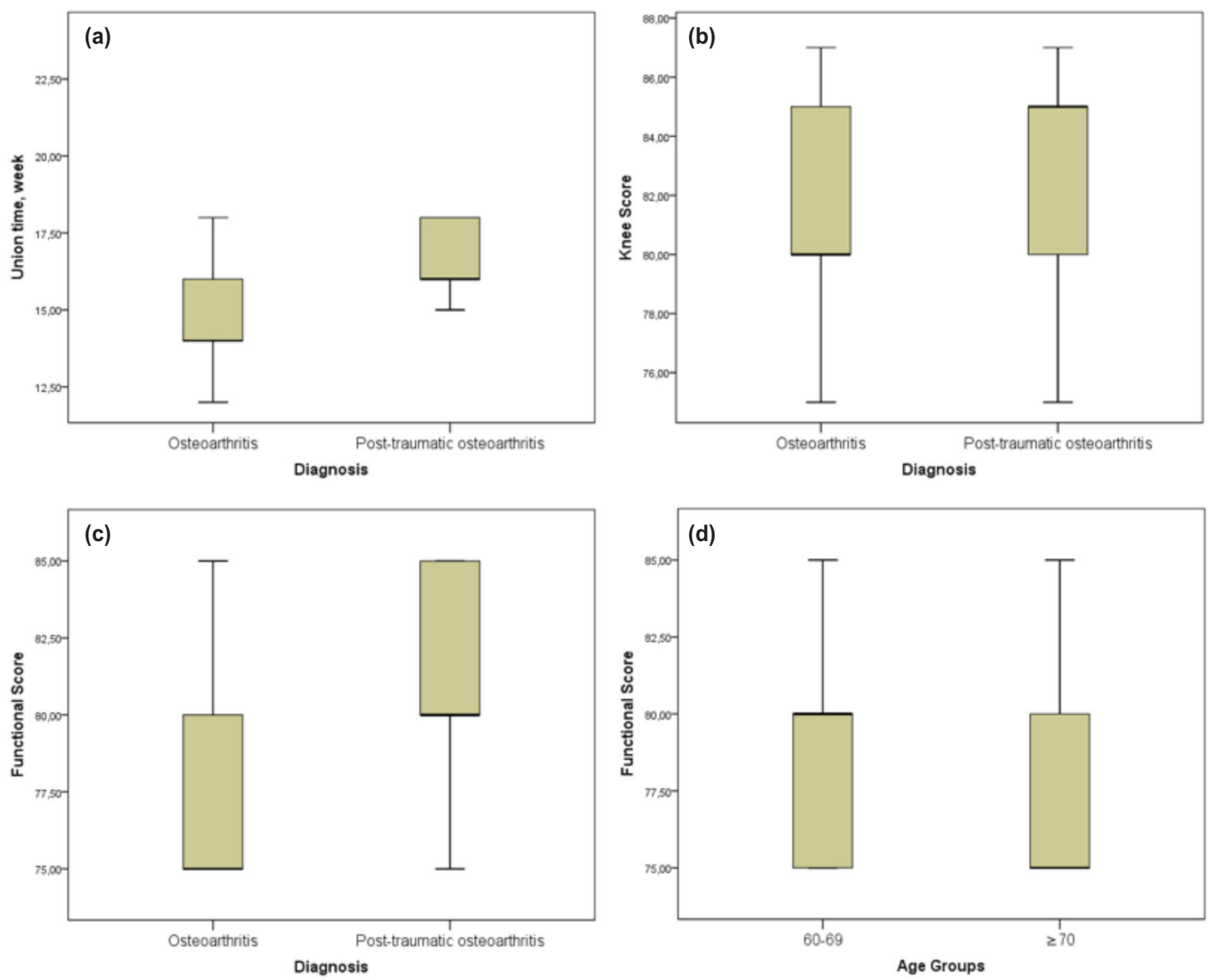

Fig. 3: (a) Union time in diagnosis groups. (b) Knee score in diagnosis groups. (c) Functional scores in diagnosis groups. (d) Functional scores in age groups.

and component and joint instability with mal-alignment ${ }^{1}$. Tibial PPFs were evaluated according to Felix Classification, and according to this classification, fractures are divided into four. Type 1 is tibial plateau fracture, type 2 is metaphysial region fractures around lower point of tibial stem, type 3 is the fractures from the tibial stem to distal, and type 4 is tibial tubercle fractures. Fractures with intact prosthesis are type A, fractures with cut-off is type B, and intra-operative fractures are type $\mathrm{C}^{19}$.

In our series, the fractures are classified as Felix type 3A in tibial fractures. Twelve of 15 supracondylar femur fractures were Lewis - Rorabeck type 2 and 3 was type 1 fractures.

The goals of treatment in periprosthetic fracture surgery are to achieve a painless and stable knee joint, thus achieving painless and stable knees with excellent fit and range of motion. This ensures a good range of motion ${ }^{8,20,21}$. Conservative treatments with brace or cast result in reduced range of motion. Early return to the previous functional state can be achieved after the locking is secured by a good alignment with the plates. Agarwal et $a l^{8}$ reported the mean Knee Society Knee Score was 85 (range, 75-89) and the functional score was 76 (range, 70-85) in their patients. In this current study we found Knee Society Knee Score was 81.4 (range, 75-87) and the mean functional score was 78.75 (range, 75-85).

There were some limitations of this study. Firstly, it was a retrospective analysis and the number of patients was relatively small, as it included the results of a single centre and was a rare condition. In addition, patella fractures were excluded because only periprosthetic fractures with locking plates were examined. Prospective, comparative studies with more patients are needed in the future.

\section{CONCLUSION}

Post-operative PPF are seen as more complicated than intraoperative fractures. The aim of the revision surgery is early mobilisation and stable fixation. We have been assuming that internal fixation with LCP is a reliable treatment option for PPF with good bone reserve and stable prosthesis. In addition, the duration of union after periprosthetic fracture surgery is shorter in the degenerative osteoarthritis group compared to post-traumatic arthritis. 


\section{CONFLICT OF INTEREST}

The authors declare no potential of conflict of interest.

\section{REFERENCES}

1. Marya SKS, Kacker S, Singh C. Periprosthetic fractures-a review article. J Clin Orthop Trauma. 2011; 2(1): 3-11.

2. Ritter MA, Thong AE, Keating EM, Faris PM, Meding JB, Berend ME, et al. The effect of femoral notching during total knee arthroplasty on the prevalence of postoperative femoral fractures and on clinical outcome. J Bone Joint Surg Am. 2005; 87(11): 2411-14.

3. Tharani R, Nakasone C, Vince KG. Periprosthetic fractures after total knee arthroplasty. J Arthroplasty. 2005; 20: $27-32$.

4. Lombardo DJ, Siljander MP, Sobh A, Moore DD, Karadsheh MS. Periprosthetic fractures about total knee arthroplasty. Musculoskelet Surg. 2019; 104(2): 135-43. doi: 10.1007/s12306-019-00628-9

5. Insall JN, Dorr LD, Scott RD, Scott WN. Rationale of the Knee Society clinical rating system. Clin Orthop Relat Res. 1989; (248): 13-4.

6. Rorabeck CH, Taylor JW. Classification of periprosthetic fractures complicating total knee arthroplasty. Orthop Clin North Am. 1999; 30(2): 209-14. doi: 10.1016/s0030-5898(05)70075-4

7. Felix NA, Stuart MJ, Hanssen AD. Periprosthetic fractures of the tíbia associated with total knee arthroplasty. Clin Orthop Relat Res. 1997; (345): 113-24.

8. Agarwal S, Sharma RK, Jain JK. Periprosthetic fractures after total knee arthroplasty. J Orthop Surg. 2014; 22(1): $24-9.7$.

9. Ricci WM, Loftus T, Cox C, Borrelli J. Locked plates combined with minimally invasive insertion technique for the treatment of periprosthetic supracondylar femur fractures above a total knee arthroplasty. J Orthop Trauma. 2006; 20(3): 190-6.

10. Kregor PJ, Stannard JA, Zlowodzki M, Cole PA. Treatment of distal femur fractures using the less invasive stabilization system: surgical experience and early clinical results in 103 fractures. J Orthop Trauma. 2004; 18: 509-20.

11. Chettiar K, Jackson MP, Brewin J, Dass D, Butler-Manuel PA. Supracondylar periprosthetic femoral fractures following total knee arthroplasty: treatment with a retrograde intramedullary nail. Int Orthop. 2009; 33: 981-5. doi: 10.1007/s00264-008-0587-y

12. Fulkerson E, Tejwani N, Stuchin S, Egol K. Management of periprosthetic femur fractures with a first generation locking plate. Injury. 2007; 38: 965-72. doi: 10.1016/j.injury.2007.02.026

13. Gliatis J. Periprosthetic distal femur fracture: plate versus nail fixation. Opinion: intramedullary nail. J Orthop Trauma. 2007; 21(3): 220-1. doi: 10.1097/01.bot.0000257496.39483.cd

14. Akdeniz H, Atalay IB, Kaya V, Ozanlagan E, Togral G. Surgery and functional results of pathological fractures of long bones of lower extremities in malignant tumors. Acta Oncol Tur. 2016; 49(1): 13-20. doi: 10.5505/aot.2016.65487

15. Davison BL. Varus collapse of comminuted distal femur fractures after open reduction and internal fixation with a lateral condylar buttress plate. Am J Orthop (Belle Mead NJ). 2003; 32(1): 27-30.

16. Figgie MP, Goldberg VM, Figgie HE 3rd, Sobel M. The results of treatment of supracondylar fracture above total knee arthroplasty. J Arthroplasty. 1990; 5(3): 267-76. doi: 10.1016/s0883-5403(08)80082-4

17. Faimali M, Karuppiah SV, Hassan S, Swamy G, Badhe N, Geutjens G. Mortality and morbidity associated with periprosthetic fracture after total knee replacement. J Ortho Bone Disord. 2018; 2(2): 000155

18. Zalzal P, Backstein D, Gross AE, Papini M. Notching of the anterior femoral cortex during total knee arthroplasty characteristics that increase local stresses. J Arthroplasty. 2006; 21(5) :737-43. doi: 10.1016/j.arth.2005.08.020

19. Yoon SH, Oh CW. Treatment of peri-prosthetic fracture about total knee replacement. J Korean Fract Soc. 2011; 24(2): 206-11. doi: 10.12671/jkfs.2011.24.2.206

20. Ozturk R, Arıkan S. Comparison of locking plate and cephalomedullary nailing in unstable proximal femur fractures. J Clin Anal Med. 2018; 9(1): 18-22. doi: 10.4328/JCAM.5250

21. Norrish AR, Jibri ZA, Hopgood P. The LISS plate treatment of supracondylar fractures above a total knee replacement: a casecontrol study. Acta Orthop Belg. 2009; 75(5): 642-8. 